\title{
Research Paper: Effects of Social Skills Training on Social Participation Among Physical and Motor Disabled People in Educational Complex Charity, Raad Center
}

\author{
*Paria Pourhossein Hendabad ${ }^{1}$, Mostafa Eghlima ${ }^{1}$, Malihe Arshi ${ }^{1}$, Zahra Taghinezhad ${ }^{1}$
}

1. Department of Social Work, University of Social Welfare and Rehabilitation Sciences, Tehran, Iran.

Received: 7 May 2016 Accepted: 26 Aug. 2016

Keywords:

Social participation, Physical disabled, Social skills
Cteat On: Pourhossein Hendabad P, Eghlima M, Arshi M, Taghinezhad Z. [The Effects of Social Skills Training on Social Participation Among Physical and Motor Disabled People in Educational Complex Charity Raad Center (Persian)]. Journal of Rehabilitation. 2017; 17(4):308-317. http://dx.doi.org/ 10.21859/jrehab-1704308

http://dx.doi.org/ 10.21859/jrehab-1704308

\begin{abstract}
Objective Disability is a general concept that relate to a person's deprivations resulting from defects (disorder) disability. In other words, any lack or reduction in equal level of opportunity to participate in social life is called disability. As a result of increasing population of physical and motor disabled, which is mainly caused by genetic factors, congenital and adventitious such as trauma, accidents, diseases and aging, active social participation of a large number of people will be restricted, but on the other hand, considering ICF classification which emphasize on participation of people with disabilities, the importance of addressing the social participation of people with physical and motor disabilities will be more prominent. Thus helping the individuals with physical and motor disabilities develop their skills for good life, increased confidence in dealing with problems and also help them in development of emotions and social skills seems necessary for successful social participation. So the purpose of this study was to investigate the effectiveness of social skills training on social participation among physical and motor disabled people in educational Raad charity rehabilitation complex.

Materials \& Methods This research was semi-experimental with pre-test and post-test pattern and control group. The statistical population in this study included all students of Raad center (195 members of which 120 were females and 75 males). Sixty physical and motor disabled members were selected randomly and divided into two groups (intervention and control). Social skills program was implemented in the experiment group in 8 sessions, each of 90 min duration. To assess the social participation of participants, the social participation and demographic questionnaires were filled by the participants before the first session and after the last session. Validity and reliability for social participation were 0.788 and 0.87 , respectively. The data were analyzed by software SPSS version 16 . Descriptive statistics such as mean, frequency, standard deviation, and inferential statistics including Mann-Whitney $U$ test, Levene's test, Kolmogorov-Smirnov test, t-dependent and independent t-tests and covariance (ANCOVA) were used Results Significant differences were found between total social participation before and after social skills training $(P<0.05)$ and between total social participation and the institutional and non-institutional subscales for trained and untrained participants $(P<0.05)$.

Conclusion According to the results of this study, holding training sessions on social skills can be effective for the physical and motor disabled people. So, it is likely that the widespread use of this intervention by professionals can relieve the limitations of participation of people with physical and motor disability.
\end{abstract}

\section{* Corresponding Author:}

Paria Pourhossein Henda bad, MSc.

Address: Department of Social Work, University of Social Welfare and Rehabilitation Sciences, Koodakyar Ave, Daneshjoo Blvd, Evin, Tehran, Iran.

Tel: +98 (912) 4714105

E-Mail: paria.pourhossein@gmail.com 


\title{
بررسى تأثير آموزش مهارتهاى اجتماعى بر مشاركت اجتماعى معلولان جسمىوحركتى مجتمع آموزشى نيكوكارى رعد مركز
}

\author{
"بريا يورحسين هندآباد'، مصطفى اقليما'، مليحه عرشى'، زهرا تقىنثزاد' \\ 1- اكروه مددكارى اجتماعى، دانشكاه علوم بهزيستى و توانبخشى، تهران، ايران.
}

\begin{abstract}
حكs

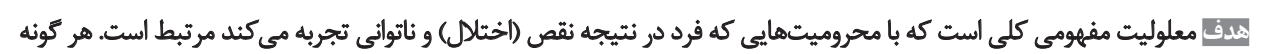

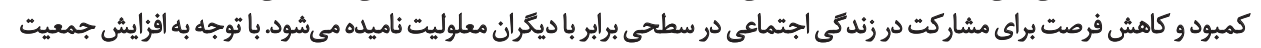

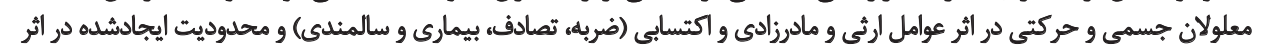

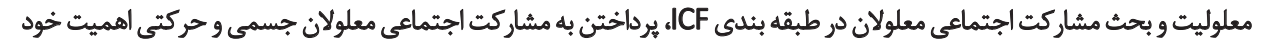

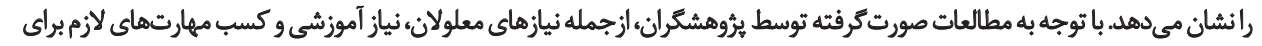

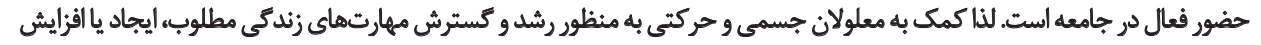

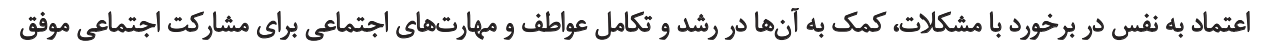

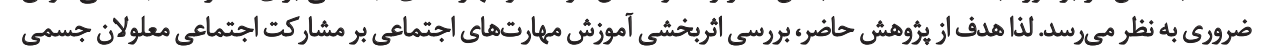

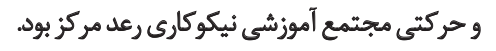

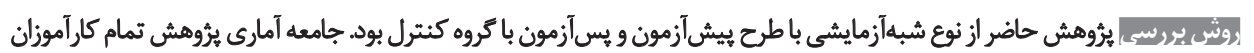

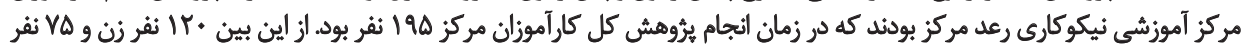

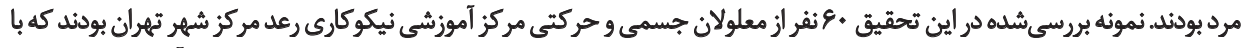

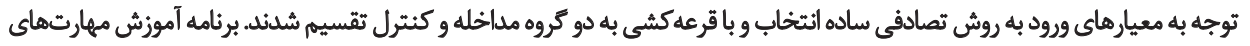

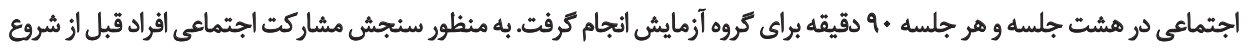

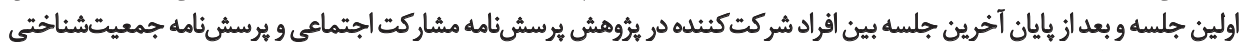

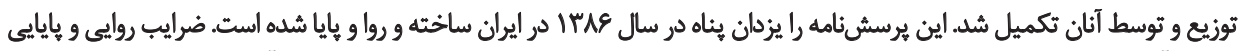

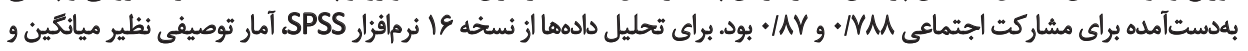

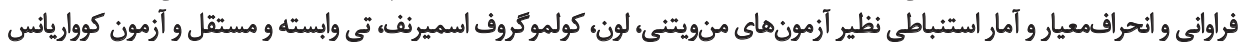
آنوا استفاده شد.

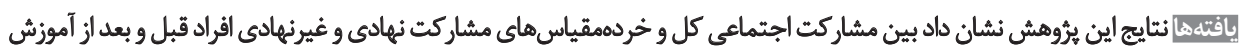

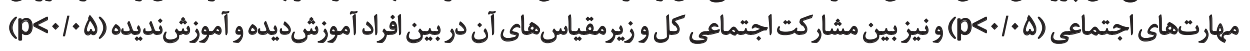
ت تفاوت آمارى معنادارى وجود دارد.

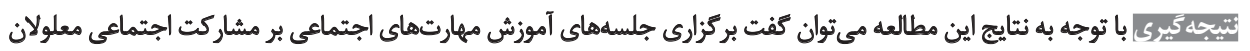

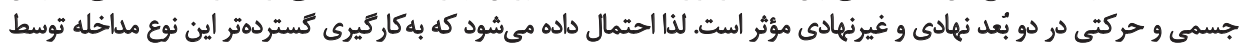

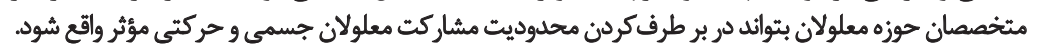

تاريخ دريافت:شارديبهشت هوش

تاريخ يذيرش: ه شهريور هو
كليدوارٔها: مها:

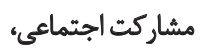

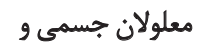

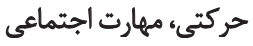

در زندكى كم شود، اين واقعه مشخصهاى شخصى نيست؛ بلكه

مقدمه

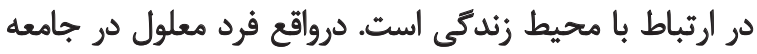

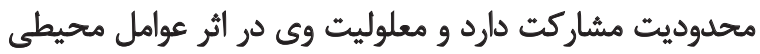

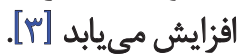
معلوليت مفهومى كلى محسوب مى ابشود كه با محروميتهايى سلامت تعاريف كستردهاى دارد كه طبق تعريف نوين آن

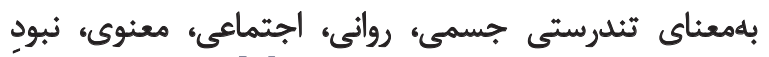

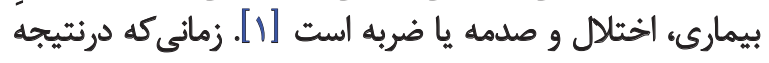
نقص و ناتوانى محدوديتى در سلامتى رخ دهد كه في فعاليت شخص 도. 


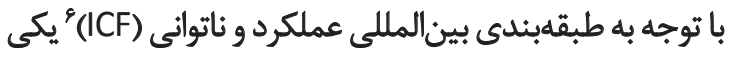

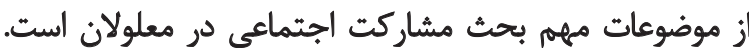

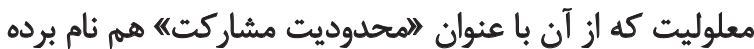

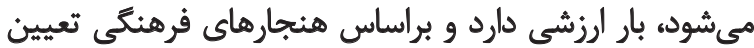

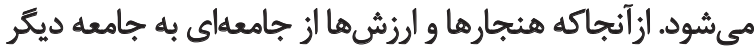

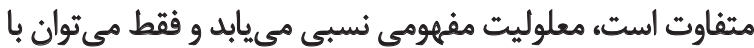

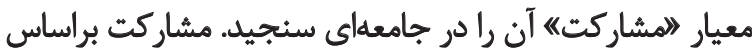

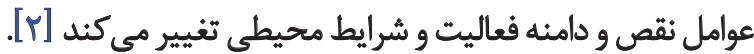
بايد توجه داشت كه معلولان جسمى حركتى براى انجام كارهاى

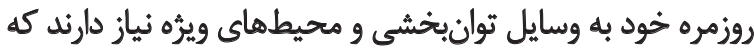

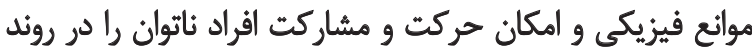

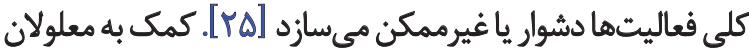

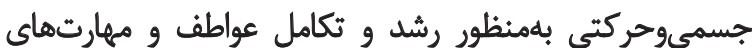

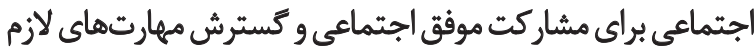

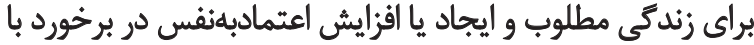

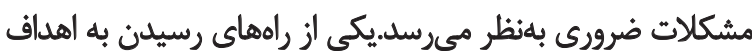

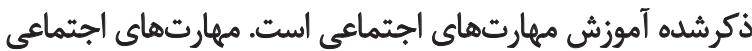

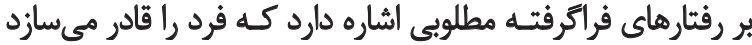

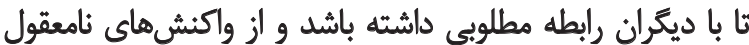

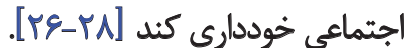

مهارتهاى اجتماعى طيف كستردهاى از رفتارها از قبيل

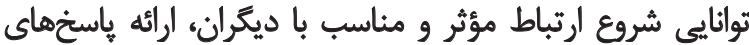

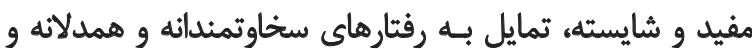

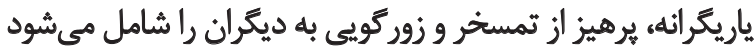

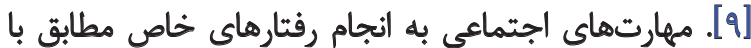

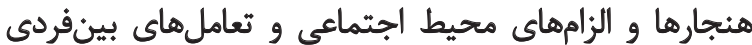

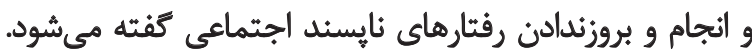

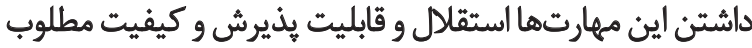

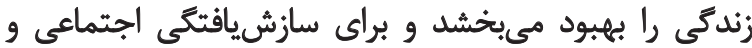

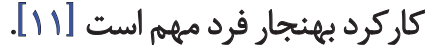

فقدان آموزش و عدم دريافت خدمات و فرصتهاى اجتماعى باعي

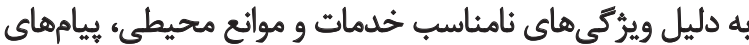

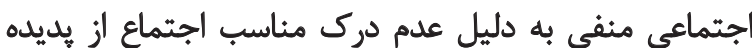

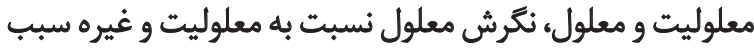

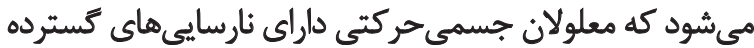

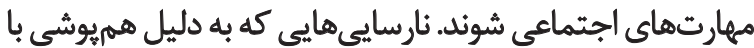

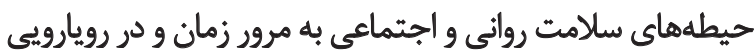

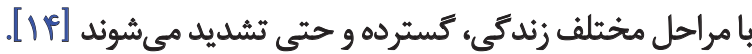

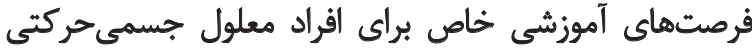

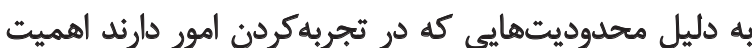

6. International Classification of Functioning and Disability 7. Social skills
مرتبط است كه فرد در نتيجه نقص (اختلال) و ناتوانى تجربه

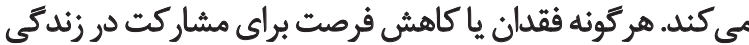

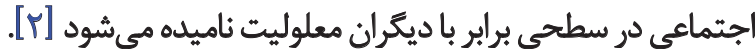

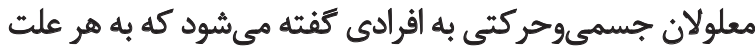

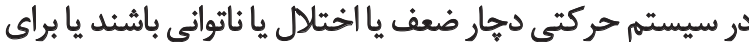
تحرك به يارهاى وسايل كمكى نياز داشته باشني

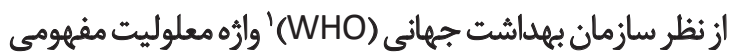

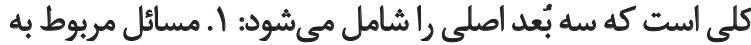

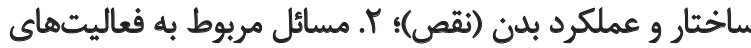

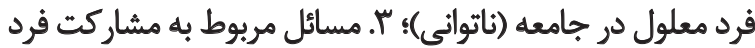

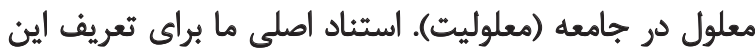

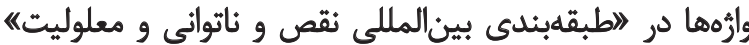

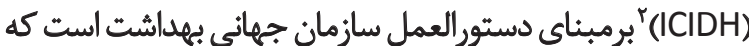

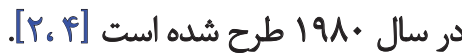
براساس آمارى كه سازمان جهانى بهداشت اعلام كرده است،

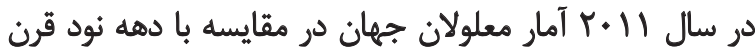

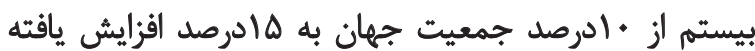

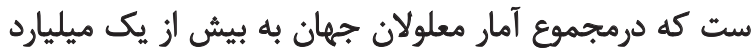

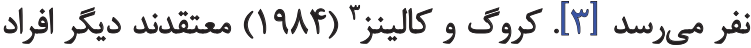

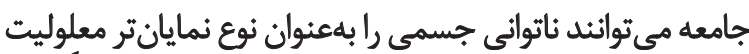

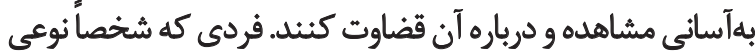

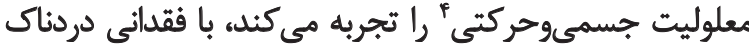

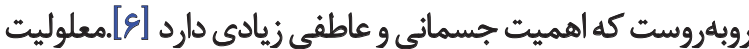

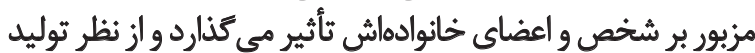

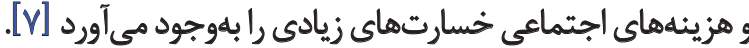

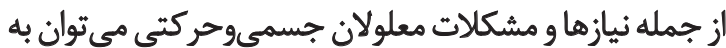

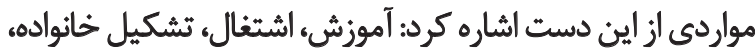

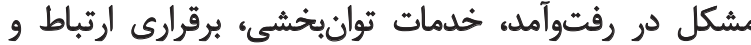

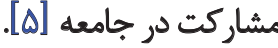
همانطوركه كفته شد، مشاركت اجتماعى هنيز يكى از نيازهاى

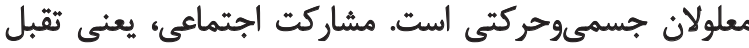

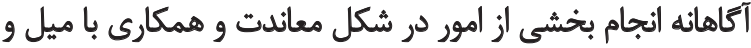

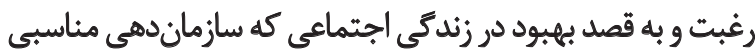

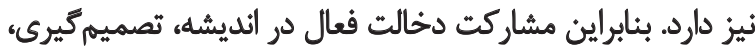

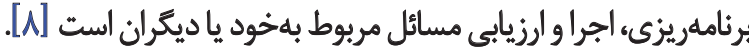

1. World Health Organization (WHO)

2. International Classification of Impairment, Disability and Handicap (ICIDH)

3. Kruege and Collins

4. Physical handicap

5. Social participation 


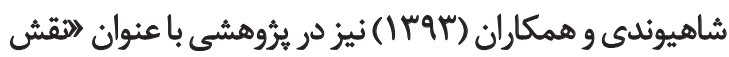

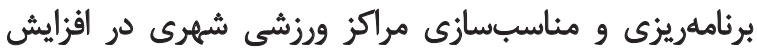
فعاليتهاى بدنى و مشاركت اجتماعى

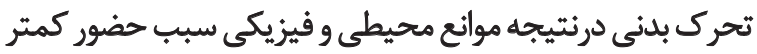
معلولان جسمى حركتى در بين ساير افراد و مشاركت إينى اجتماعيى

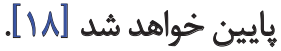

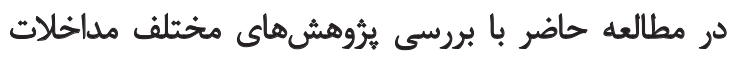

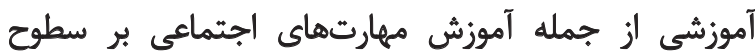

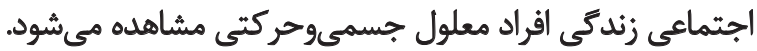

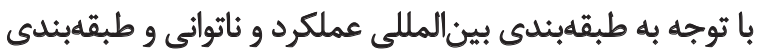

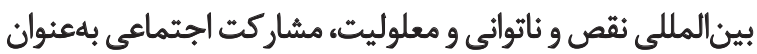

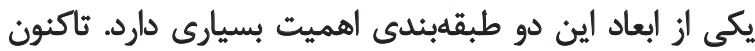

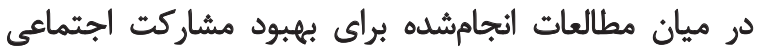

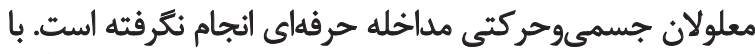

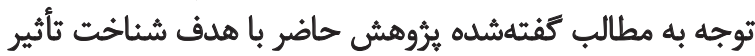

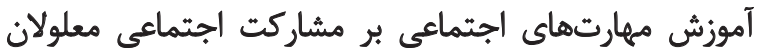

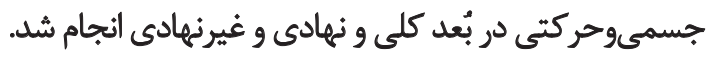

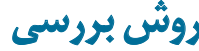

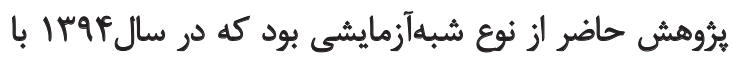

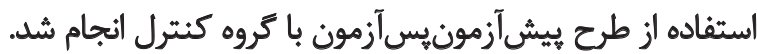

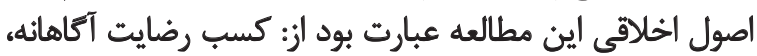

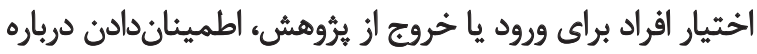

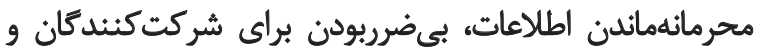

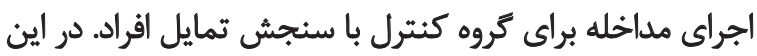

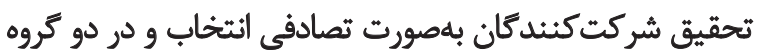

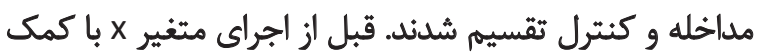

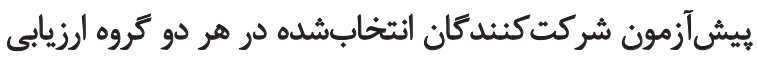

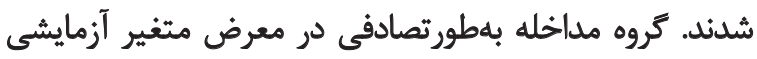

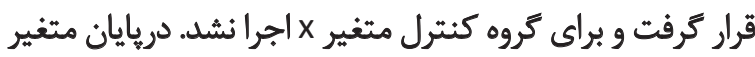

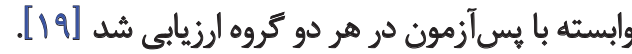

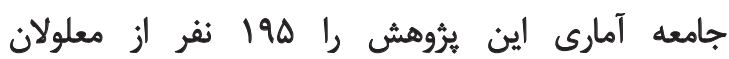

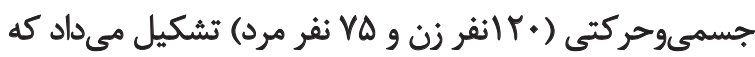

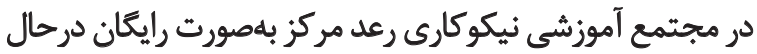

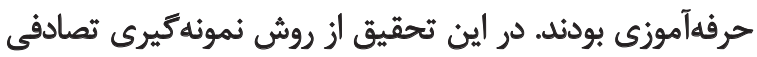

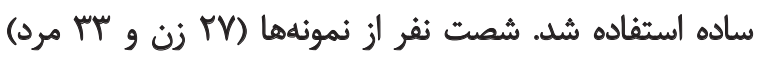

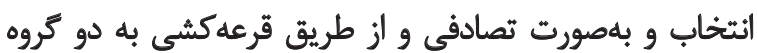

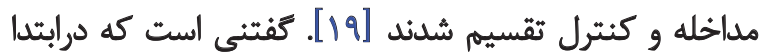

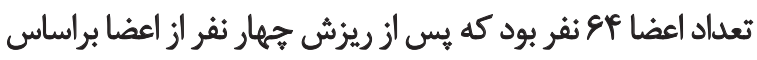

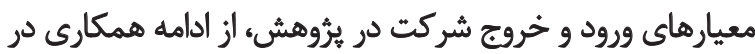
ئروهش كنار كذاشته شدند.

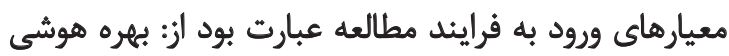

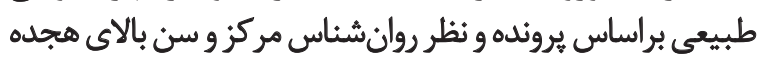

بيشترى دارد [IT]]

از جمله مطالعات مرتبط با موضوع مطالعه حاضر مىتوان به

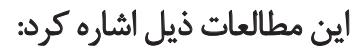

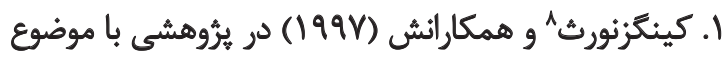

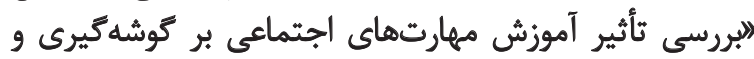

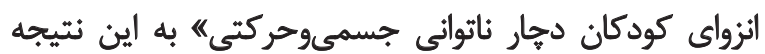

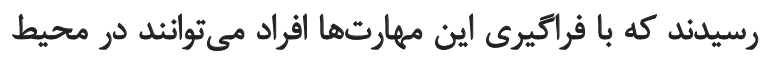

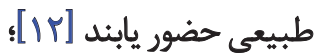

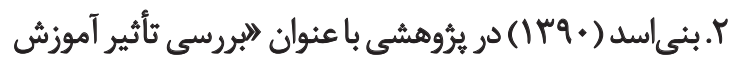

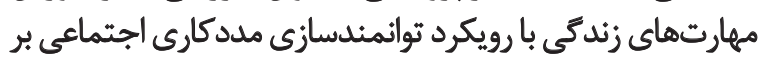

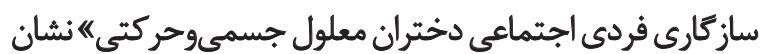

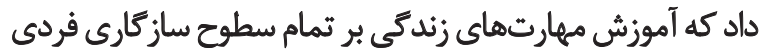

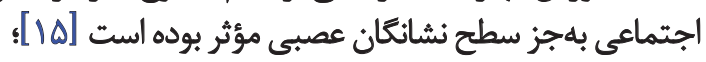

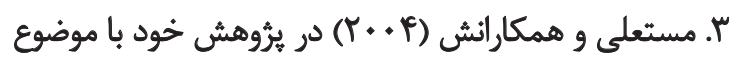

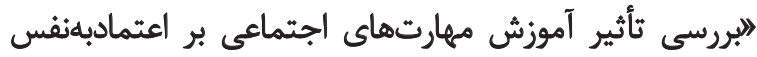

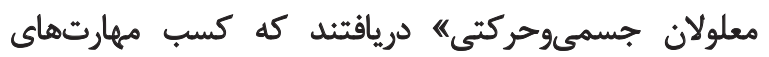

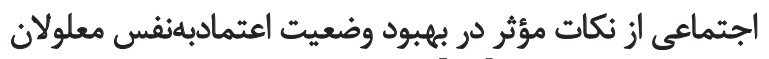
جسمىوحركتى است [19]؛

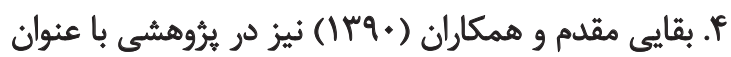

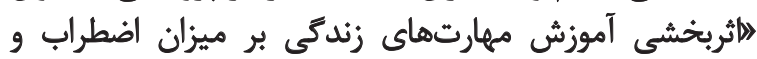

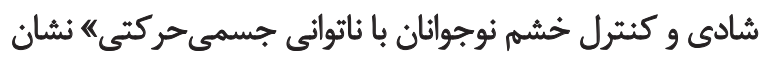

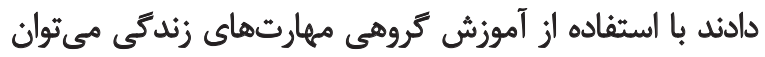

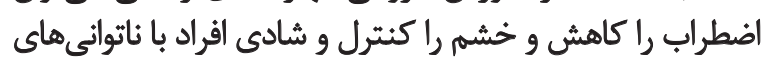

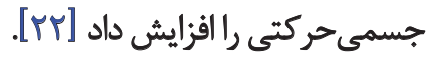

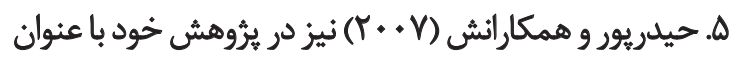

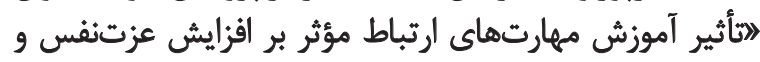

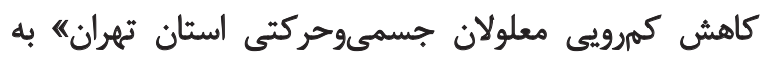

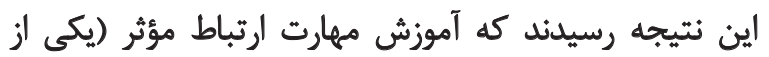

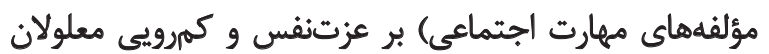

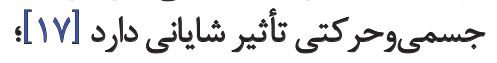

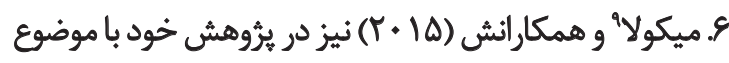

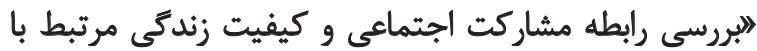

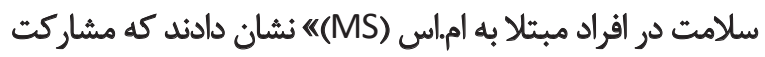

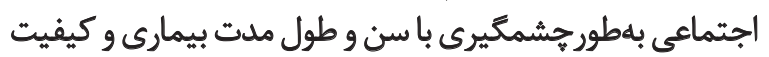

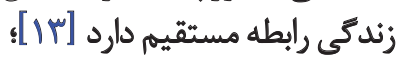

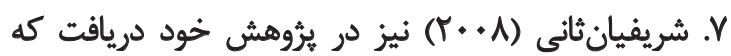

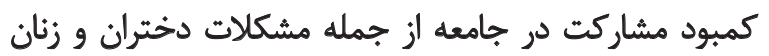

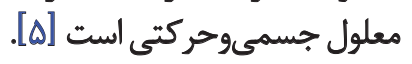

8. Kingsnorth

9. Mikola 


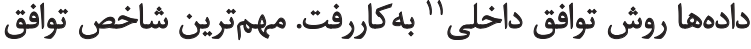

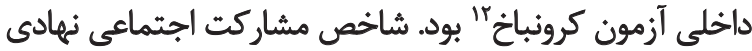

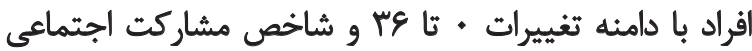

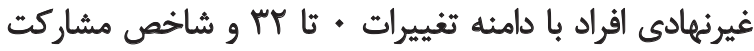
اجتماعى كل افراد با دامنه تغييرات • تأ ه \$ بود.

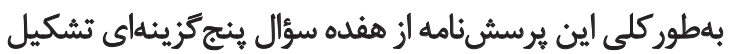

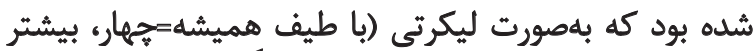

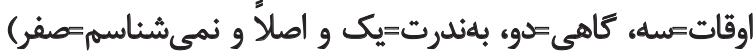

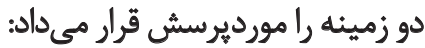
1. سنجش ميزان مشاركت اجتماعى نهادى يا رسمى (كويهها: (1) F. IY-1F, 19.IV

r. سنجش ميزان مشاركت اجتماعى غيرنهادى يا غير رسمى

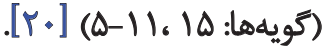

در اين يُروهش مداخله شامل دو مرحله بود: ا. تشكيل گروها؛

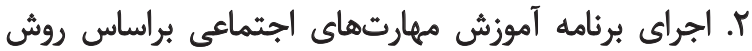

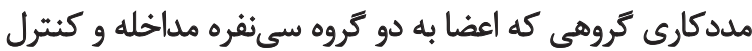

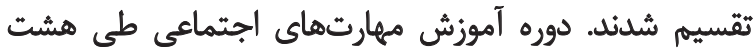

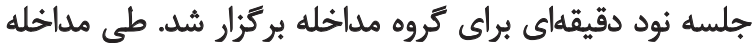

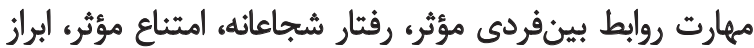

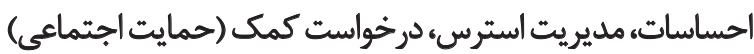

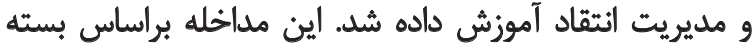

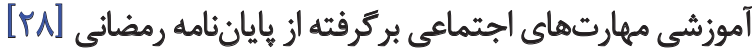
و كتابهاى مختلف در اين زمينه با همكارى استادان مدانئ مددكاري

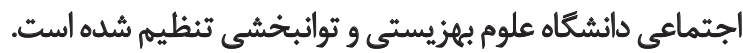
يس از كذشت دو هفته از يايان مداخلات آموزشى، دادههاى

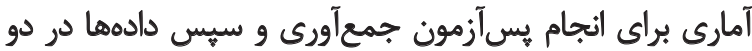

11. Internal consistency

12. Cronbach coefficient

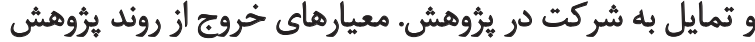

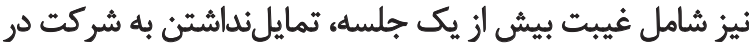
ئروهش و خروج از مركز بود بئ

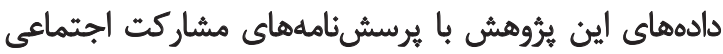

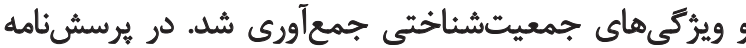

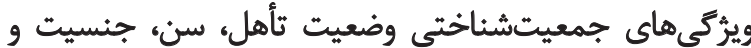

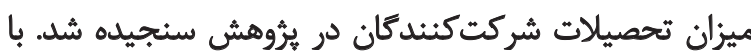

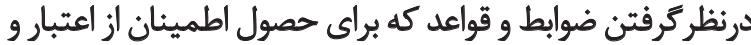

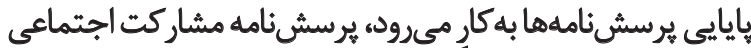

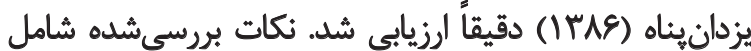

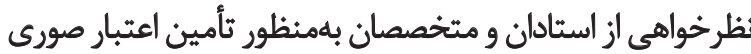

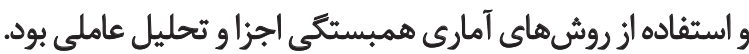

برسش بامه در دو مرحله بيش آزمون شد. سبيس براساس نتايج

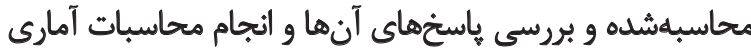

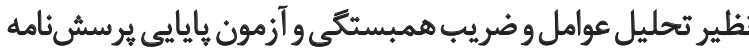

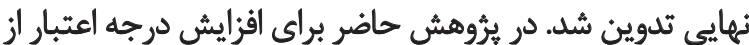

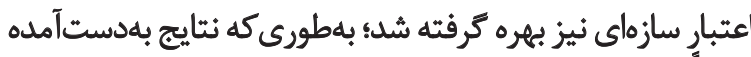

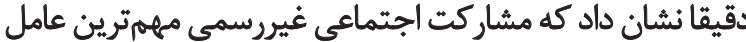

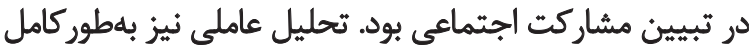

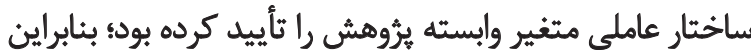

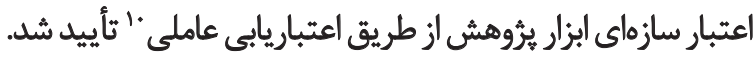
نتيجه تحليل عاملى براي هفده مورد طيف مشاركت اجتماعى

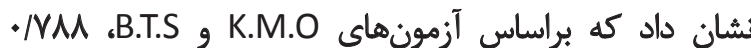

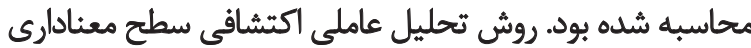

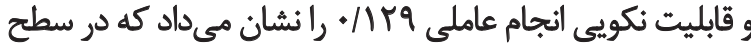

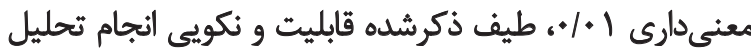

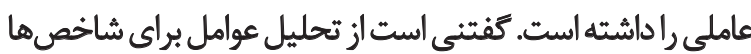
و متغيرهاى مستقل نيز استفاده شده است. براى سنجش إيايايى

10. Factor validity

جدول ا. ميانكين و انحرافمعيار نمرات زيرمقياس مشاركت اجتماعى كل و نهادى و غيرنهادى در كروههاى مداخله و كنترل در ييش آزمونيس آزمون.

\begin{tabular}{|c|c|c|c|c|}
\hline \multirow{2}{*}{ تعداد } & يسآزمون & يشيش آزمون & \multirow{2}{*}{ كروه } & \multirow{2}{*}{ متغير } \\
\hline & ميانكين (انحرافمعيار) & ميانكين (انحرافمعيار) & & \\
\hline r. & $r) / r a(r / m)$ & TM/TA(T/.9) & ملاخله & \multirow[b]{2}{*}{ مشاركت الجتماعى كل } \\
\hline r. & $m / N(r / 19)$ & $r / N E(T / N)$ & كنترل & \\
\hline r. & $T Y / R I(P / P Y)$ & $11 / T^{m} \cdot(1 / F 5)$ & مباخله & \multirow{2}{*}{ مشاركت اجتماعى نهادى } \\
\hline r. & $\| Y / \Delta \Delta(Y M U)$ & $\mid r / \Delta A(Y / * A)$ & كتثرل & \\
\hline r. & $\mid V \cdot P(T / \Delta))$ & $1.1+A(1 / \pi \Delta)$ & مباخله & \multirow{2}{*}{ مشاركت اجثماعى غيرنهادى } \\
\hline r. & $\| / T r(r / \cdot \cdot)$ & $W / M(T / \Lambda \Delta)$ & كتترل & \\
\hline
\end{tabular}


جدول r. ييشفرض همكنى واريانس نمرات مشاركت اجتماعى كروه اول در پِسآزمون با توجه به متغيرهاى بررسىشده در آزمون لوين.

\begin{tabular}{|c|c|c|c|}
\hline \multicolumn{3}{|c|}{ آزمون لوين براي برابرى واريانسها } & \multirow{3}{*}{ كتروها } \\
\hline $\mathrm{F}$ & درحه آنادي & معن دائ & \\
\hline mer & 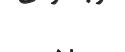 & . & \\
\hline
\end{tabular}

توانبخنىى

جدول ب. نتايج آزمونكولموكروفاسميرنوف براى فرض طبيعىبودن متغير مشاركت اجتماعى در دو كروه مداخله و كنترل.

\begin{tabular}{|c|c|c|c|}
\hline Pقدار P P P & آماره كولموكروف|سميرنوف & أزمون & كروه - اه \\
\hline IFTT & 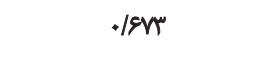 & ييش آزمون & \multirow{2}{*}{ ملاخله } \\
\hline.$/ \Delta \Delta 9$ & . $/ \Delta Y$ & يسآزمون & \\
\hline$\cdot(N A I$ & . rof & ييش آزمون & \multirow{2}{*}{ 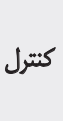 } \\
\hline$\cdot / v \cdot 1$ & .1091 & يس آآزمون & \\
\hline
\end{tabular}

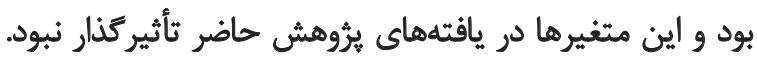

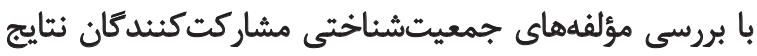

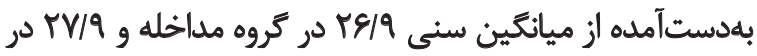

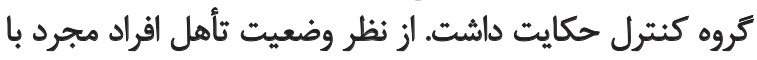

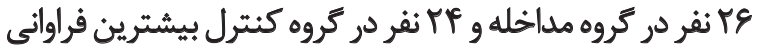

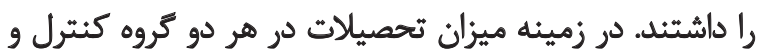

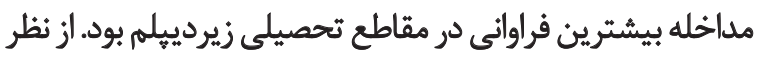

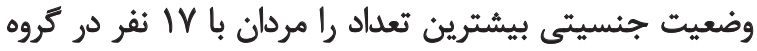
مداخله و 18 نفر در كروه كنترل داشتند.

در جدول شماره 1 ميانتين و انحراف استاندارد نمرات

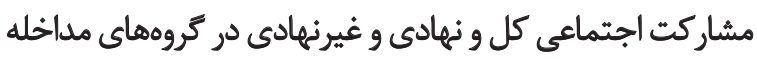

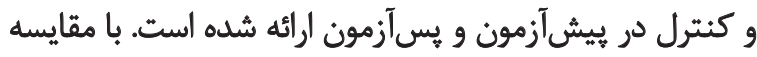

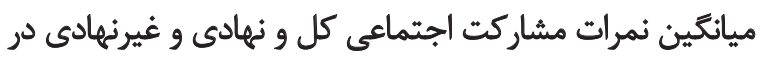

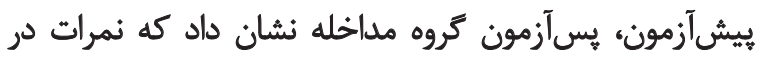

سطح توصيفى و تحليلى تجزيلوتحليل شد. براي تجزيلوتحليل

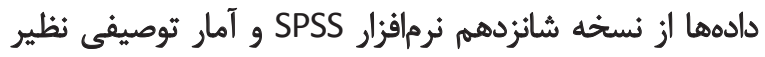

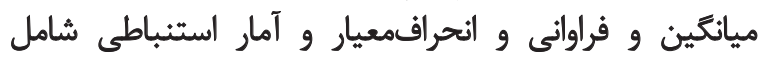

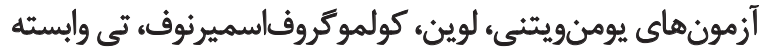

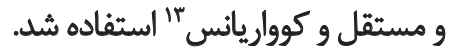

يافتهها

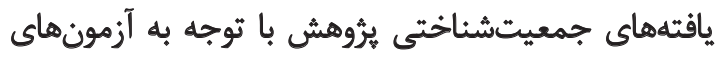

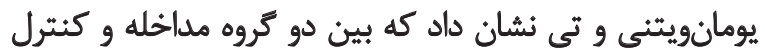

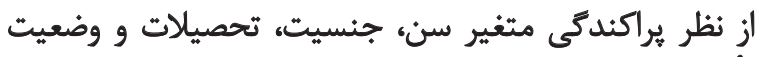

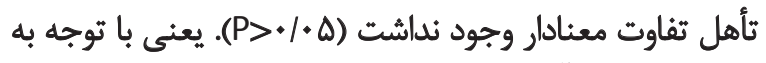

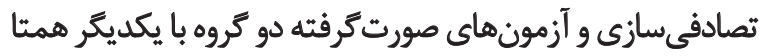

جدول F. نتايج تحليل كوواريانس مقايسه نمرات يس آزمون كروه مداخله با كروه كنترل.

\begin{tabular}{|c|c|c|c|c|c|c|c|c|}
\hline توان أمارى & اندازه اثر & Sig. & $\mathbf{F}$ & ميانكينور & آزادى & مجذوموات & منيع تغييرات & متغير \\
\hline T & 每 & / /QAT & $9 \Delta /+\varphi$ & 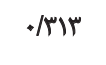 & 1 & & بيشأزمون & \multirow{2}{*}{ مشاركت الجتماعى كل } \\
\hline.$/ 9$ &.$/ 4 a$ & $.0 .+$ & IV./eg & HAQV/PI & 1 & พหAพ/P' & كروه & \\
\hline.$/ M T$ & . & . INA & ET/MT & $1 / 29$ & 1 & $1 / 99$ & ييش آزمون & \multirow{2}{*}{ مشاركث الجتماعى نهادى } \\
\hline.$/ 9$. &.$/ 41$ & .1 .18 & rea/Fq & $10 W Y N A$ & 1 & $|A| N \mid Y A$ & Sروه & \\
\hline . $/ \Delta r$ &.$/ r$ & - /AT & QNTH &.$/ 94$ & 1 &.$/ 9 V$ & ييشآزمون & \multirow{2}{*}{ ششاركت اجتماعى غيرنى } \\
\hline.$/ 9 \Delta$ & .148 & . & $M \mid Q / r \Lambda$ & grum & 1 & ETIM & كروه & \\
\hline
\end{tabular}


جدول ه. نتايج آزمون تى مربوط به مقايسه ميانكين نمرات دو كروه مداخله وكنترل ازنظر ميزان مشاركت اجتماعى كل ونهادى وغيرنهادى در بيشآزمونيس آزمون.

\begin{tabular}{|c|c|c|c|c|c|c|c|c|}
\hline احتمال & أرجاديه & $\begin{array}{c}\text { أزمون tols } \\
\text { t }\end{array}$ & ميائتين & (انحرافمعيار) & تعداد & كروه ها & مثغير & \\
\hline$\cdot / / r$ & $\mathbb{M}$ & $\Delta / \mu \varphi^{\prime}$ & $-r / r \wedge$ & 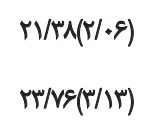 & $\begin{array}{l}r . \\
r .\end{array}$ & كنترل آزمايش & هشاركت اجتماعى كل & \\
\hline$* / 1+4$ & $\mathbb{M}$ & T/MeT & $-1 / T \Lambda$ & 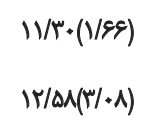 & $\begin{array}{l}r . \\
r .\end{array}$ & كُمترل & هشاركث اجتماعى نهادى & $\frac{c}{c}$ \\
\hline.$/ 1 F$ & $M$ & $T / \Delta Q$ & $-1 / 1$ & $\begin{array}{l}1.1 \cdot N(1 / T \Delta) \\
11 / N(T / A \Delta)\end{array}$ & $\begin{array}{l}r . \\
r .\end{array}$ & كنيترل آزمايش & ششاركت اجتماعى غيرنهادى & \\
\hline$\%$ & $\mathbb{M}$ & V/DFA & $I V / \Delta A$ & $\begin{array}{l}r v / r \Delta(r / r u) \\
r / W(r / 19)\end{array}$ & $\begin{array}{l}r . \\
r .\end{array}$ & كثترل & مشاركت اجتماعى كل & \\
\hline$\%$ & $\Delta$ & $r / 110$ & q/VE & $\begin{array}{l}T / T \backslash(F / F Y) \\
T / \Delta \Delta(\Psi / W U)\end{array}$ & $r$. & كنترل & هشاركت اجتماعى نهادى & $\frac{c}{c}$ \\
\hline$\%$ & $\mathbb{M}$ & T/QRT & V/AT & $\begin{array}{l}19 \cdot F(T / \Delta 1) \\
11 / T r(T / * \cdot)\end{array}$ & $\begin{array}{l}r . \\
r .\end{array}$ & كثترل & مشاركت اجتماعى غيرنهادى & \\
\hline
\end{tabular}

عدد ه • • بود كه برابرى واريانس هاى دو تروه و كمتربودن سطح

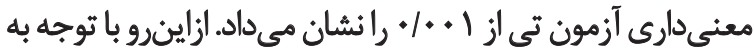

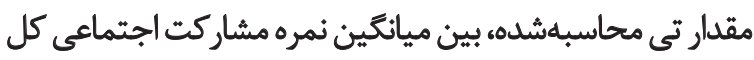

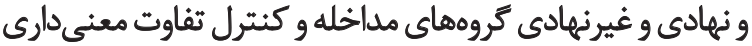
وجود داشت. - و ونهادي

بحث

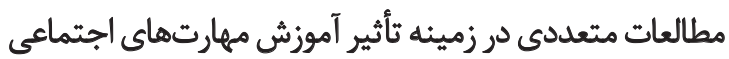

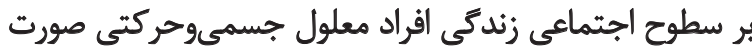

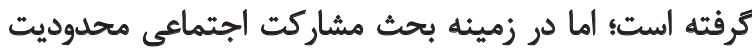

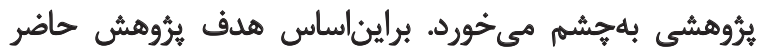

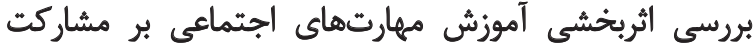

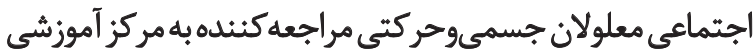

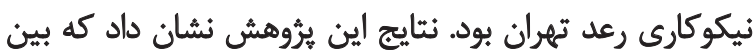

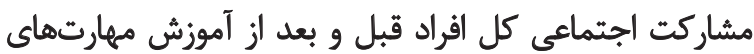

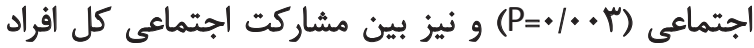

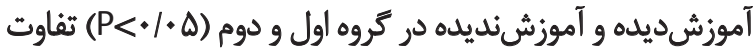

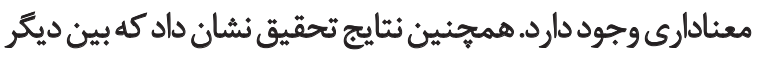

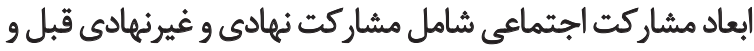

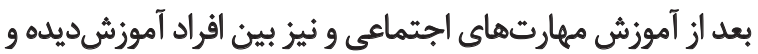

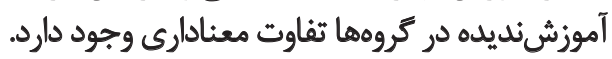
يُروهش اندكى بهطورمستقيم به آموزش مهارتهاي اجتماعى

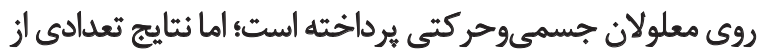

يس آزمون در مقايسه با بِيش آزمون افزايش يافته است.

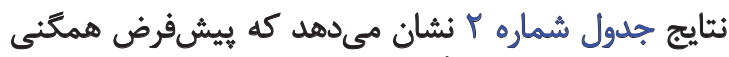

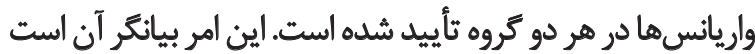

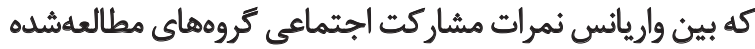

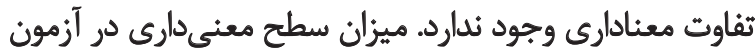

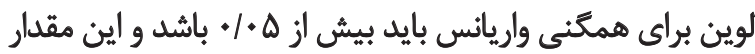
هرجه به يك نزديكتر باشد، ارزش بيشترى بارئ بارد.

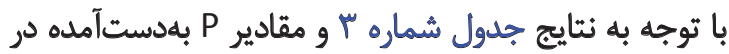

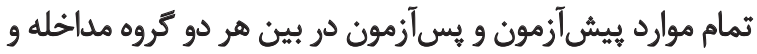

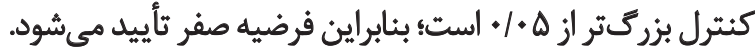

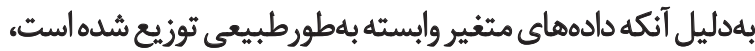

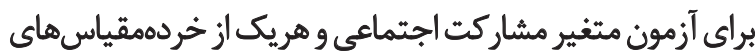

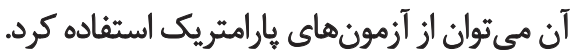
كتايج جدول شماره f نشان داد بين ميزان مشاركت اجتماعى

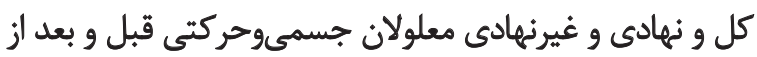

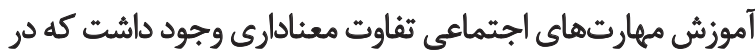

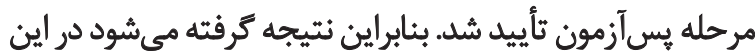

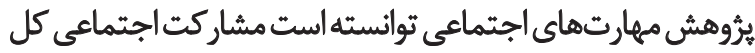

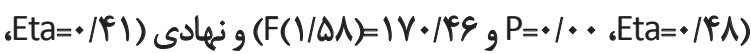

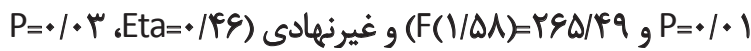
(F( ) معلولان جسمىوحركتى را افزرايش دهد. براساس جدول شماره ه مقدار احتمال آزمون لوين بزركتر از 


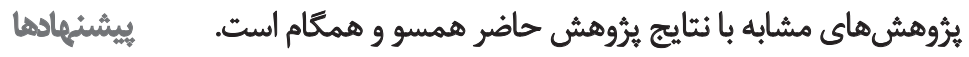

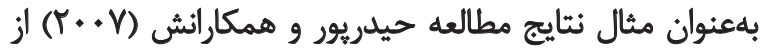

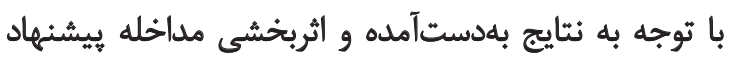

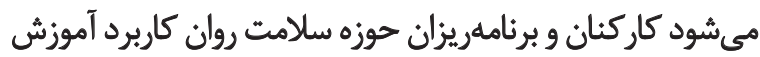

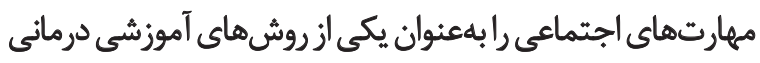

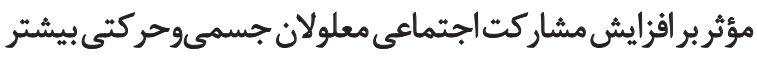

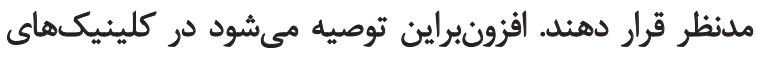

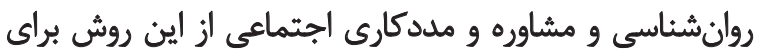

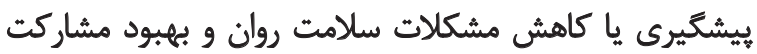

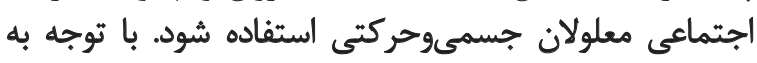

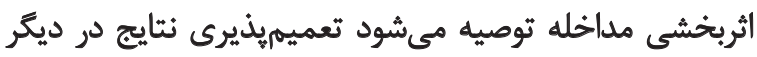

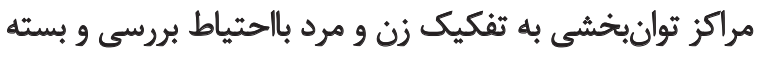
آموزشى مجزا براى زنان و مردان فراهم شودي وندي

$$
\text { تشكر و قدردانى }
$$

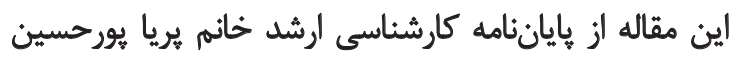

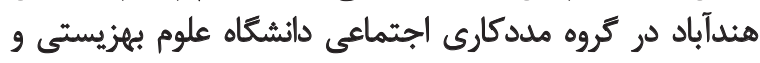

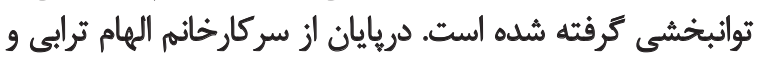

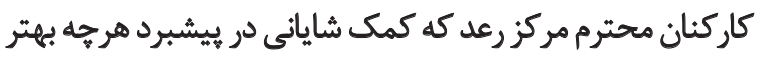

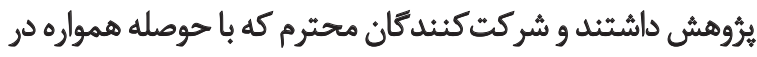

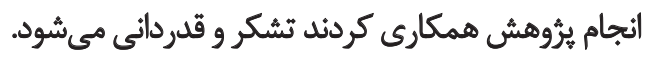

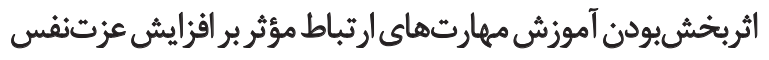

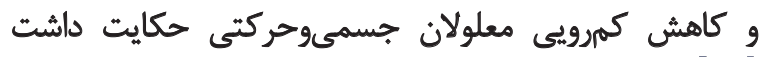

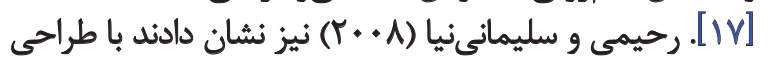

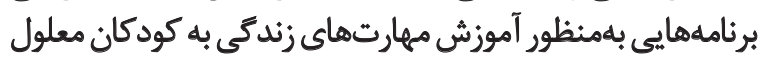

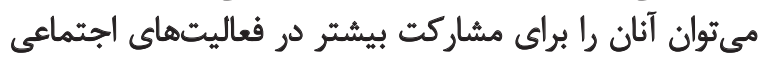

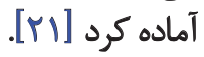

يافتهاى اين يروهش با نتايج برخى تحقيقات مشابه خارجى

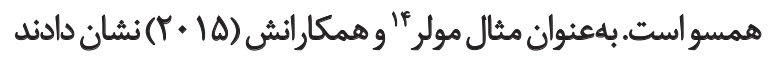

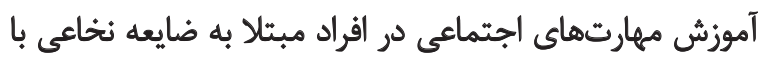

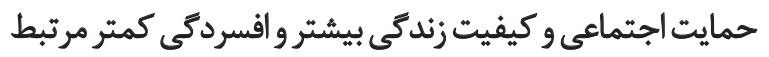

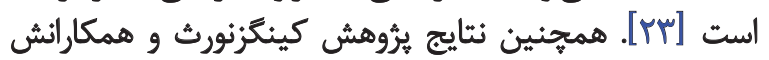

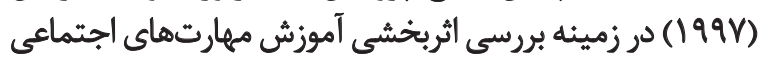

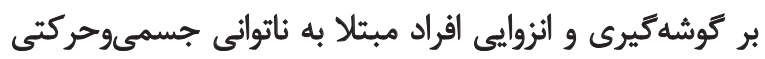

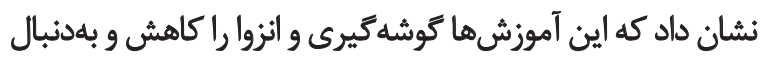

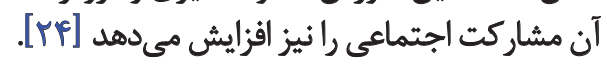

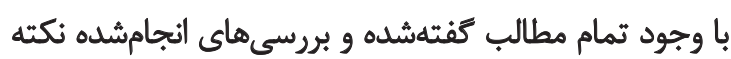

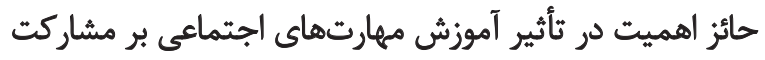

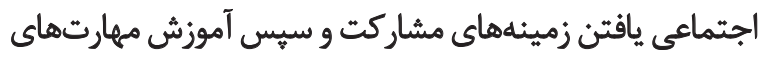

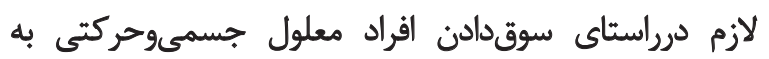

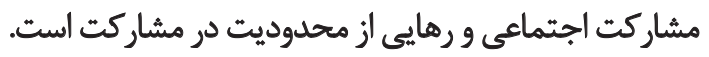

\section{تثيجهكَيرى}

براساس يافتههاى يثوهش مي توان نتيجه كرفت كه آموزش

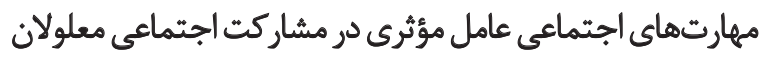

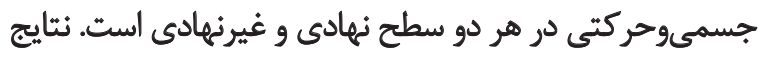

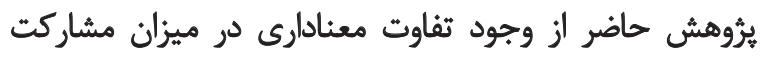

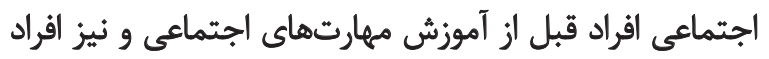
آموزشديده و آمورش أنديد أموريد حكايت دارد.

مجلموديتها

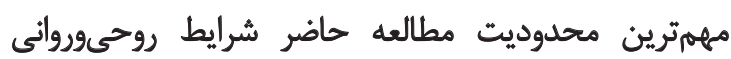

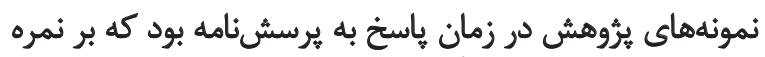

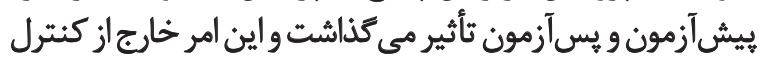

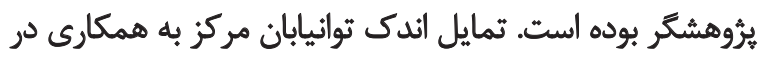

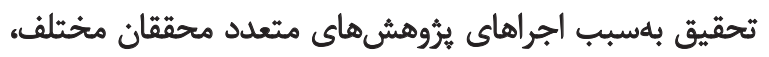

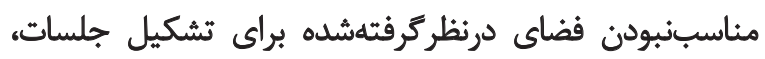

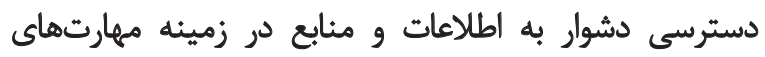

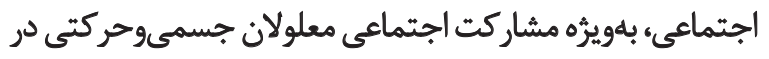

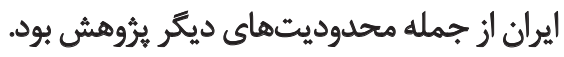




\section{References}

[1] Davatgaran, K. [Classification of functioning, disability and health (Persian)]. Tehran: Welfare Organization; 2014

[2] Karimi H. [Rehabilitation groups with special emphasis on the social worker services (Persian)]. Tehran: Roshd Publications; 2011.

[3] Karimi Dermani H. [Rehabilitation principles (Persian)]. Tehran: Roshd Publications; 2007.

[4] Jebeli K. [Sociology of disability, sociological explanation of discrimination against persons with disabilities (Persian)]. Tehran: Elmi Publications; 2012.

[5] Sharifiyan Sani M, Sajjadi H, Tolouei F, Kazem A. [Girls and women with physical disabilities: needs and problems (Persian)]. Journal of Rehabilitation. 2008; (2):41-48.

[6] Kruege DW, Collins LB. Rehabilitation psychology: comprehensive textbook. Maryland: Aspen systems Corporation; 1984.

[7] Noori A, Moradi A, Amiri S, Malekpour M, Molavi H. [Self-efficacy group training on quality of life and entrepreneurial behavior of women with disabilities and mobility (Persian)]. Journal of Social Studies of Women. 2008; 7(3):71-98.

[8] Aghabakhshi H. [Street children and runways and vulnerable social issue (Persian)]. Paper presented at: Role of social work in social damage control; 2005 October 4; Tehran, Iran.

[9] Wais T, Alyson JB. The impact of depression on social skills. Journal of Nervous \& Mental Disease. 2004; 192(4):260-68. doi: 10.1097/01.nmd.0000120884.60002.2b

[10] Nobakht Z, Rassafiani M, Rezasoltani P, Sahaf R, Yazdani F. Environmental barriers to social participation of children with cerebral palsy in Tehran. Iranian Rehabilitation Journal. 2013; 11:40-45.

[11] Hoseinkhanzade A, Yaghobnezhad S. [Review the social skills necessary for students with special needs in environment Job (Persian)]. Journal of Exceptional Education. 2011; 106:4-17

[12] Kingsnorth S, Healy H, Macarthur C. Preparing for adulthood: a systematic review of life skill programs for youth with physical disabilities. Journal of Adolescent Health, 2007; 41(4):323-32. doi: 10.1016/j.jadohealth.2007.06.007

[13] Mikula P, Nagyova I, Krokavcova M, Vitkova M, Rosenberger J, Szilasiova J, et al. Social participation and health-related quality of life in people with Multiple Sclerosis. 2015; 8(1):29-34. doi: 10.1016/j.dhjo.2014.07.002

[14] Heidaripour M, Mashhadi A. [Effectiveness of social skills training on emotional intelligence, physical-motor disability (Persian)]. Journal of Research in Rehabilitation Sciences. 2012; 8(3):571580 .

[15] Abazari Z, Mirjani Aghdam A, Cheraghi Zanjani A. [Factors influencing the participation of students in the teaching-learning process from the perspective of faculty members (Persian)]. Journal of Rehabilitation, 2015; 16(3):262-269.

[16] Mostalami F, Hoseinian S, Yazdi M. [The effects of social skills training to increase girls' confidence in Tehran blind (Persian)]. Journal of Research in Exceptional Children. 2004; 18(4):437-50.
[17] Heydarpour S, Dokaneyifard F, Bahari S. [The Impact of teach ing effective communication skills on self-seteem and reduction of shyness among the physically challenged in tehran (Persian)]. Journal of New Ideas in Educational Science. 2007; 3(4):41-52.

[18] Shahivandi A, Masoud M, Soltani T, Soltani M. [The role of planning and tailoring of urban sport facilities in increasing physical activity and community participation a case study of Arak city's citizens with hearing and motor disabilities (Persian)]. Middle Eastern Journal of Disability Studies. 2014; 4(1):50-58.

[19] Rafie H, Sajjadi S, Noori R, Noroozi S, Narenjiha H, Farhadi H, et al. [Interdisciplinary research methods in addiction and other social problems and deviations (qualitative and quantitative) (Persian)]. Tehran: Danzhe Publication; 2007.

[20] Yazdanpanah L. [Barriers to social participation of Tehran citizens (Persian)]. Journal of Social Welfare. 2006; 7(26):105-130.

[21] Rahimi A, Soleimaninia L. [The effect of life skills training on increasing children social participation (Persian)]. Journal of Social Welfare. 2008; 8(30-31):313-31.

[22] Baghaei-Moghadam G. Malekpour M. Amiri S, Mowlavi H. [The effectiveness of life skills training on anxiety, happiness and anger control of adolescence with physical-motor disability (Persian)]. Journal of Behavioral Sciences. 2011; 5(4):305-10.

[23] Müller R, Peter C, Cieza A, Post MW, Van Leeuwen CM, Werner CS, et al. Study Group. Social skills: a resource for more social support, lower depression levels, higher quality of life, and participation in individuals with spinal cord injury? Archives of Physical Medicine \& Rehabilitation. 2015; 96(3):447-55. doi: 10.1016/j. apmr.2014.09.006

[24] Van Vugt ES, Deković M, Prinzie P, Stams GJ, Asscher JJ. Evaluation of a group-based social skills training for children with problem behavior. Children \& Youth Services Review. 2013; 35(1):162-67. doi: 10.1016/j.childyouth.2012.09.022

[25] Khosravi N. [The relationship between social support and quality of life of physically disabled in Raad educedation centers (Persian)] [MA thesis]. Tehran: University of Social Welfare \& Rehabilitation Sciences; 2015.

[26] Ramezani Lashti H. [Determining the efficacy of social skills training in treatment of drug addiction in patients referring to "Tehran Clinic" (Persian)] [BA thesis]. Tehran: University of Social Welfare \& Rehabilitation Sciences; 2012.

[27] Barati H, Tajrishi M, Sajedi F. The effect of social skills training on socialization skills in children with down syndrome. Iranian Rehabilitation Journal. 2012; 10(1):35-38.

[28] Rashedi V, Gharib M, Yazdani AA. Social participation and mental health among older adults in Iran. Iranian Rehabilitation Journal. 2014; 12(1):9-13. 
